\title{
Article \\ Knowledge and Consumption Habits Related with White Crowberries (Corema album L.)
}

\author{
Aida Moreira da Silva ${ }^{1,2}$ (D) Maria João Barroca ${ }^{1,2, *}$ and Raquel P. F. Guiné ${ }^{3}$ (D) \\ 1 Unidade de I\&D Química-Física Molecular, Department of Chemistry, University of Coimbra, \\ 3004-535 Coimbra, Portugal; aidams@esac.pt \\ 2 Polytechnic Institute of Coimbra, Coimbra College of Agriculture, Department of Food Technology, Bencanta, \\ 3045-601 Coimbra, Portugal \\ 3 CERNAS Research Centre, Department of Food Industry, Polytechnic Institute of Viseu, \\ 3504-510 Viseu, Portugal; raquelguine@esav.ipv.pt \\ * Correspondence: mjbarroca@esac.pt
}

Citation: Moreira da Silva, A.;

Barroca, M.J.; Guiné, R.P.F

Knowledge and Consumption Habits Related with White Crowberries (Corema album L.). Appl. Sci. 2021, 11, 5463. https://doi.org/10.3390/ app11125463

Academic Editor: Andrea Salvo

Received: 7 May 2021

Accepted: 11 June 2021

Published: 12 June 2021

Publisher's Note: MDPI stays neutral with regard to jurisdictional claims in published maps and institutional affiliations.

Copyright: (c) 2021 by the authors. Licensee MDPI, Basel, Switzerland. This article is an open access article distributed under the terms and conditions of the Creative Commons Attribution (CC BY) license (https:/ / creativecommons.org/licenses/by/ $4.0 /)$.

\begin{abstract}
This study investigated the knowledge and consumption habits related with white crowberries ("camarinhas" in Portuguese) among the Portuguese population. It consisted of a questionnaire survey, undertaken on a sample of 501 participants, higher than 18 years old. For the treatment of data, basic descriptive statistics were used, complemented with the Mann-Whitney U test to assess some associations between categorical variables. Moreover, a tree classification analysis was carried out using a classification and regression tree (CRT) algorithm with cross-validation and a factor analysis was also used to treat the data. The results indicated that the majority of participants know the "camarinha" berry but the level of knowledge decreases from senior adults to young adults. On the other hand, the knowledge and overall perception about their nutritive value, sensorial characteristics and health benefits are low. Regarding the consumption of crowberries, it was found that more than half of the participants did not eat them, and $31.9 \%$ ate them only around once a year, mainly fresh, being hand-harvested from the wild by the participants. Furthermore, it was observed that the Portuguese considered that the information about crowberries is scarce, which could justify that only a small part of the participants recognized this plant as vulnerable, due to loss of its habitat, mainly by human actions and owing to lack of information. To fill the gap of information observed in Portuguese people, it is hoped that the project (IDEAS4life) that supports this work could contribute to increase the knowledge about this species and also to alert for the need of preserving this endogenous plant of the Southern European Atlantic coast.
\end{abstract}

Keywords: Corema album; small berries; white crowberries; consumption habit; health benefits; Portugal

\section{Introduction}

Corema album (L.) D. Don (Ericaceae) is an endemic shrub of Atlantic coastal dunes of Iberian Peninsula and its fruits (Portuguese white crowberries, Atlantic pearls, beachberries, camariñas in Spanish or "camarinhas" in Portuguese) (Figure 1a,b)) have been used for centuries in traditional medicine or as a food ingredient. Indeed, the use of this plant and fruit in human culture dates back to the Early Neolithic period, as evidenced in species features documented in historical written sources and current archaeobotanical research places [1]. The dioecious and perennial shrub is a drought-adapted plant that thrives in a wide range of coastal soils but grows preferentially in soils with percentages of sand around 70\%, low levels of inorganic and organic nutrients, and $\mathrm{pH}$ between 5.6 and 7.8 [2]. The flowering and fruiting of C. album occurs from February to August and the beginning of ripening is in June [3]. 


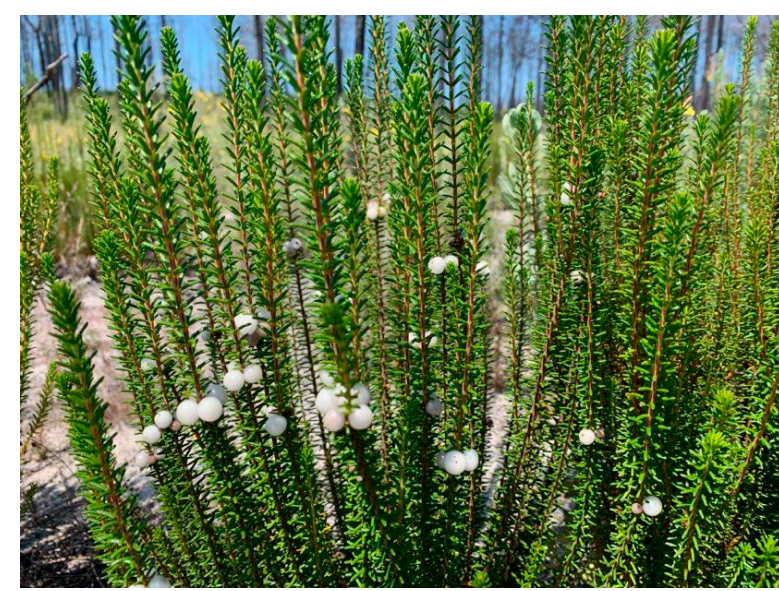

(a)

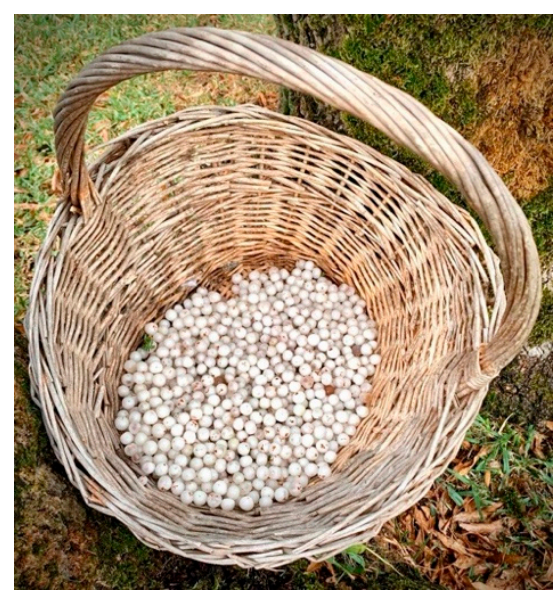

(b)

Figure 1. Endemic shrub of Atlantic coastal dunes of Iberian Peninsula: (a) Corema album (L.) D. Don (Ericaceae) shrub and (b) its small fruits (Portuguese white crowberries) in a traditional basket.

In the first half of the last century, Corema album plant was one of the most conspicuous shrubs in the Iberian Atlantic sand dunes but its fruits never became a formal commercial crop. Nowadays, the climate change impacts and the growing pressure from anthropogenicorigin disturbance has caused the loss of its natural ecosystems. However, the crowberry has the potential to be an interesting niche of berries in the market of commercial crops, because of its peculiar white color, novelty, and nutritive and bioactive compounds [3-6].

The berries, white as basic color but with the possibility of developing a pinkish tinge, are quasi-spherical fruits with a small diameter ( 5 to $10 \mathrm{~mm}$ ), a weight up to $0.66 \mathrm{~g}$, a thick woody endocarp and usually have three seeds $[6,7]$. The water-rich berries, with a moisture content higher than $83 \%$, have high levels of fiber (around $40 \%$, dry matter), total sugars (62.80\%, dry matter) and low protein levels [7-11]. In general, crowberries are more acidic and less sweet than other berries such as blueberries, raspberries or blackberries, but have a distinctly fresh taste and an agreeable lemony flavor [7-13].

C. album presents high levels of antioxidant activity that can be attributed to compounds such as phenolic compounds, mainly derivatives of chlorogenic acid and flavonols, including myricetin, rutin, kaempferol and hydroxycinnamic acids, p-coumaric, ferulic, caffeic, sinapinic acid derivatives, and anthocyanins [9,14]. The bioactive compounds present in berries have been associated to health benefits spanning from prevention of cardiovascular and neurodegenerative diseases (such as disorder of Parkinson's) to protection against oxidative stress, inflammation and cancer [14-17]. This evidence supports the traditional use of $C$. album in popular medicine as healthy fruits and suggests that the consumption of these berries could promote positive effects in human health and help to prevent chronic diseases. In the past, the fresh crowberries were hand-harvested by coastal people with low-income resources and sold in traditional commerce of coastal villages, among other foods or medicinal herbs [5]. However, the improvement of the economic level of the population and the loss of crowberries' natural ecosystems led to a decrease in its production and sales, limiting its harvesting to the local people who know this wild berry. In recent years, the white crowberry is an inspiration to recover lost home-made recipes, such as pearlberry jelly, pearlberry tisane and ice-cream [3], eventually sold in local markets and festivals.

This work aims to investigate the level of knowledge and consumption of the ancestral and endogenous berry of the Iberian Peninsula: the Portuguese white crowberry.

\section{Materials and Methods}

\subsection{Instrument and Data Collection}

The instrument used for this research was a questionnaire (Supplementary Material S1) which was prepared specifically for this purpose. It included 6 different parts, namely: 
(I) Sociodemographic variables (8 questions); (II) Knowledge about crowberries (2 questions, 8 items); (III) Consumption habits (5 questions); (IV) Knowledge about their nutritional composition and health effects (1 question, 10 items); (V) Social aspects related to this fruit (3 questions, 10 items).

The survey was conducted on a convenience sample, based on the facility of recruitment and willingness to answer the questionnaire. Although some limitations can be pointed out to the use of convenience samples, they also have some positive aspects and are eligible for exploratory research $[18,19]$. The sample size was calculated based on some principles, namely a 95\% confidence interval, corresponding to a level of significance of $5 \%$ and a $\mathrm{z}$ score of 1.96 . The power of the test considered corresponds to an error of $5 \%$, which corresponds to a minimum acceptable probability of preventing type II error equal to 0.05 [20,21]. The Portuguese population in 2019 (the last year available) was 10,283 thousand people, of which about $80 \%$ are adults, aged 18 years old or over [22] Considering a target population of $50 \%$ of the Portuguese adults, the sample size was calculated as 385 participants [23-25]. Hence, a minimum of 385 participants should be used to take this survey as representative and with statistical relevance. The data were collected through an internet platform and the request to fill the questionnaire was sent by different internet tools, such as email and social networks. Only participants 18 years old or more were included in the study, and other inclusion criteria were having access to internet, having a computer or other devices through which they could answer the questionnaire, being able to understand the questions and express their responses, and willingness to participate in the research voluntarily and anonymously. The participation had to express their informed consent to participate in the study, and they could only access the questionnaire after confirming the participation. Additionally, it was guaranteed that the internet tool used for the questionnaire did not record any data from the participants, like email, IP or others. All ethical issues were respected when designing and applying the questionnaire, which was approved by the Ethical Commission at the Polytechnic Institute of Viseu with reference 22/SUB/2021.

The number of responses received was 520, however, some had to be rejected due to some excluding criteria. Fourteen were rejected because the participants' age was under 18 years old (between 12 and 17 years), although having agreed to be adults in order to access the questionnaire. Another 5 participants were excluded for not residing in Portugal (one in the United States, one in France, one in Sweden, one in Mozambique and one did not declare where he lived). Hence, the final number of valid responses considered for the study was 501, which was higher than the minimum number of 385 calculated based on the above mentioned assumptions. These answers were obtained from Portuguese citizens from the following municipalities, which cover almost the entire Portuguese territory: Azores, Aveiro, Beja, Braga, Bragança, Castelo Branco, Coimbra, Évora, Faro, Guarda, Leiria, Lisbon, Portalegre, Porto, Santarém, Setúbal, Viana do Castelo and Viseu.

\subsection{Data Analysis}

To explore the data, the software SPSS V26 (IBM, Inc., Armonk, NY, UAS) and Excel 2016 were used. Descriptive tools were used for frequencies or range and to calculate mean values and the corresponding standard deviation. Additionally, statistical tests were used to evaluate possible differences between groups. Due to asymmetric group distribution, the non-parametric tests were used: Mann-Whitney U test to compare among 2 groups and Kruskal-Wallis test to compare between 3 or more groups, with pairwise multiple comparisons.

The relative influence of the sociodemographic variables on the level of knowledge about crowberries was studied by means of a tree classification analysis, using a classification and regression tree (CRT) algorithm with cross-validation [26], considering a minimum change in improvement equal to 0.001 and establishing the minimum number of cases for parent and child nodes equal to 30 and 10, respectively. 
Factor analysis (FA) was also used to treat the data. Some indicators were used to test the suitability of the data, such as the correlation matrix, the Kaiser-Meyer-Olkin measure of adequacy of the sample (KMO) and the Bartlett's test [27]. The solution was obtained through extraction Maximum Likelihood method and Varimax rotation. The number of components retained was stipulated according to the Kaiser criterion, which is equivalent to consider eigenvalues $\geq 1$. The communalities allowed assessing the percentage of variance explained by the factors extracted [28], and in the analysis were higher [29,30]. To determine the internal consistency in each factor the Cronbach's alpha $(\alpha)$ was used $[28,31]$.

A level of significance of $5 \%$ was considered in all statistical analyses.

\section{Results}

\subsection{Sociodemographic Characterization of the Sample}

The sample was composed of 376 women and 125 men. The participants were aged between 18 and 78 years old, being on average $44( \pm 14)$ years. The age of the female participants was approximately the same ( $44 \pm 14$ years) as that of the men (45 \pm 15 years). The age was classified into categories, according to: young adults (aged between 18 and 30 years), adults (aged between 31 and 50 years) and senior adults, including the elderly (aged 51 years or over). Hence, the distribution of the participants by age class was: $22.0 \%$ young adults, $38.5 \%$ adults and $39.5 \%$ senior adults.

The highest level of school completed was graduation (bachelor, master or PhD degree) for most participants (385), then 112 had completed secondary school (equivalent to 12 years of school), and only 4 participants had only achieved completion of basic school (corresponding to 9 years of school). These two last categories were merged into one containing all participants who had levels of school up to the 12th grade.

Regarding the living environment, 148 participants lived in rural areas, 292 in urban environments and 61 in suburban areas. Again, in this case, a reorganization of groups was made for better homogeneity, and therefore, the rural and suburban groups were merged, accounting for $41.7 \%$ of participants, while the urban group accounted for $58.3 \%$.

The marital status of the participants was 163 single, 267 married or living together, 63 divorced or separated, and 8 widowed. This variable was also reorganized for better group distribution, according to the following classification: those who lived with a companion (married), which corresponded to 53.3\%, and those who lived alone (single, divorced or widowed), which corresponded to $46.7 \%$.

Regarding the employment status, 354 were employed, 16 were unemployed, 78 were students, 32 were working students, and 21 were already retired. These groups were rearranged into employed (70.7\%) and others (29.3\%). Additionally, the area of professional activity was investigated, namely for some professions, and the results showed that 44 participants have a job or studies related with nutrition, 102 with food, 59 with agriculture, 36 with sales, 44 with tourism, and 316 do not relate to any of those areas.

\subsection{Knowledge about Crowberries, Their Nutritional Effects and Health Benefits}

When asked about what crowberries ("camarinhas") are, the great majority of participants gave the correct answer (79.2\% answered fruits/berries), but there were some who did not know about them (15.6\% assumed they did not know and 5.2\% thought it was something else: vegetable/salad, legume, sea product/fish, or other).

Figure 2 presents the results obtained for the level of agreement of the participants towards a number of statements aimed to evaluate the level of knowledge about general aspects linked with crowberries, measured on a 5-point Likert scale varying from totally disagree to totally agree. The participants demonstrated to be well informed about crowberries growing in bushes (78\%), from coastal areas (73\%) and sandy soils (73\%). Additionally, their aspect was familiar, since most agreed that they have a white-pink coloration (71\%) and are similar to gooseberries in size $(67 \%)$. The participants also demonstrated knowing that they are not grown on big trees (87\% disagreed with the false statement). Regarding the fact that the crowberry plants are perennial, the number of participants who knew 
about this was lower, but still corresponding to more than half (54\%). Finally, concerning the crowberries' seeds, they represent an important part of the fruit, but many participants were not aware of this fact (30\% had no opinion and $41 \%$ wrongly believed the fruits practically do not have seeds).

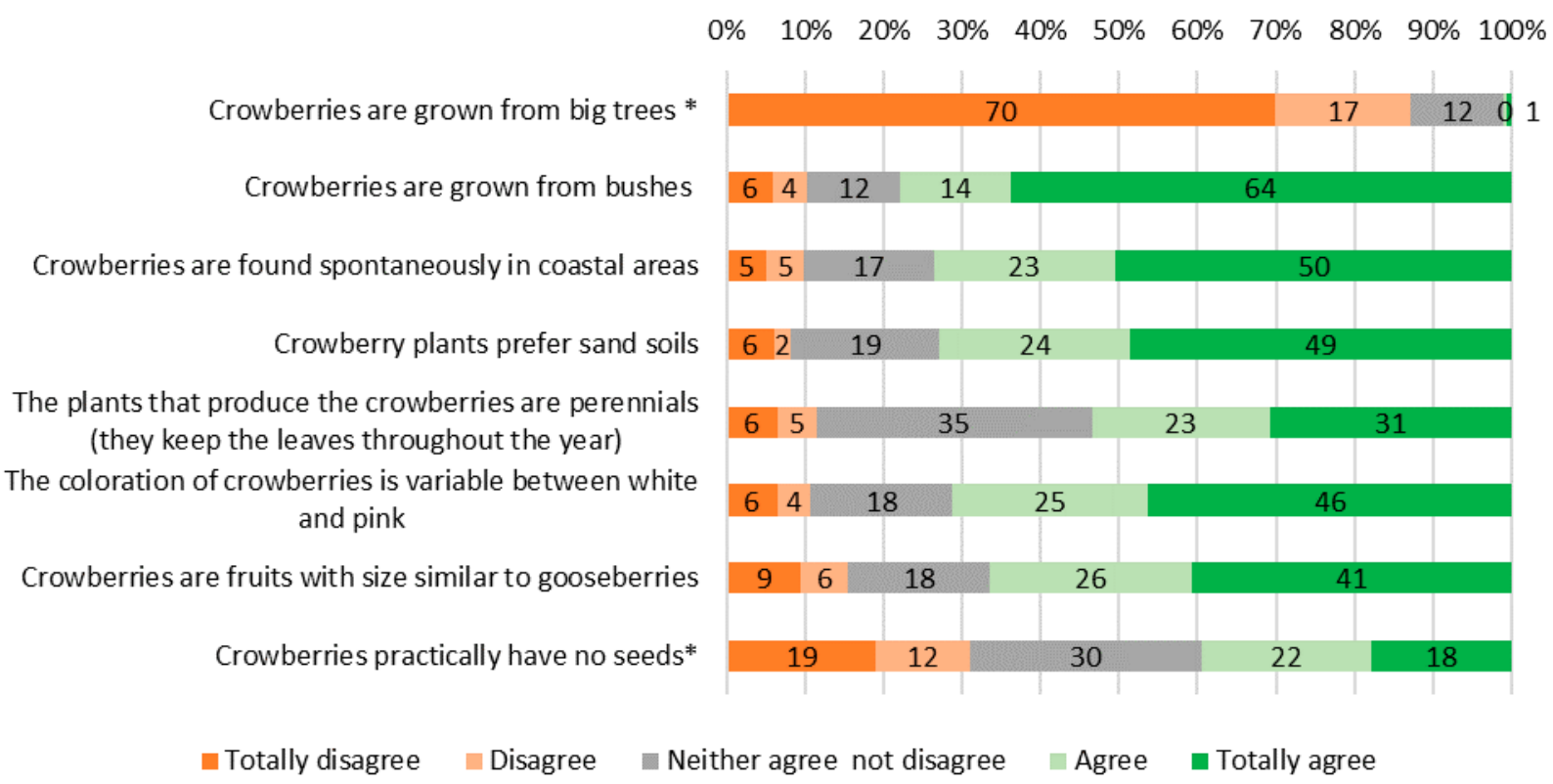

Figure 2. Level of agreement with statements related with general knowledge about crowberries (* denotes a false statement).

Figure 3 shows the level of agreement towards some statements aimed at evaluating the knowledge about the nutritive aspects of crowberries and their health effects. To this matter, the results were very indicative of a general lack of knowledge, with percentages of participants who had no opinion, i.e., neither agreed nor disagreed with the statements, varying from $28 \%$ to $80 \%$, respectively, for possible toxicity and the antipyretic effect. Those aspects that people showed to be more informed about were the berries not being toxic ( $71 \%$ disagreed with the false statement) and not causing cancer (55\% disagreement) or being rich in antioxidants (50\%) and being beneficial to regulate intestinal transit (35\%).

It is a general belief that there is not enough information available about crowberries (for $60.9 \%$ of the participants), while only $3.8 \%$ believe there is enough information about them. The remaining $35.3 \%$ had no opinion.

With respect to the sources from where the participants obtain the information, the primary source was through family / friends (for 240 participants), followed by the internet $(n=93)$, magazines $(n=18)$ and TV $(n=7)$. When asked about which media could be useful and efficient to disseminate information about crowberries, most participants believed the internet to be a very useful source of information (68\%), followed by schools/universities $(56 \%)$ and journals, books or magazines (51\%) (Figure 4$)$. 


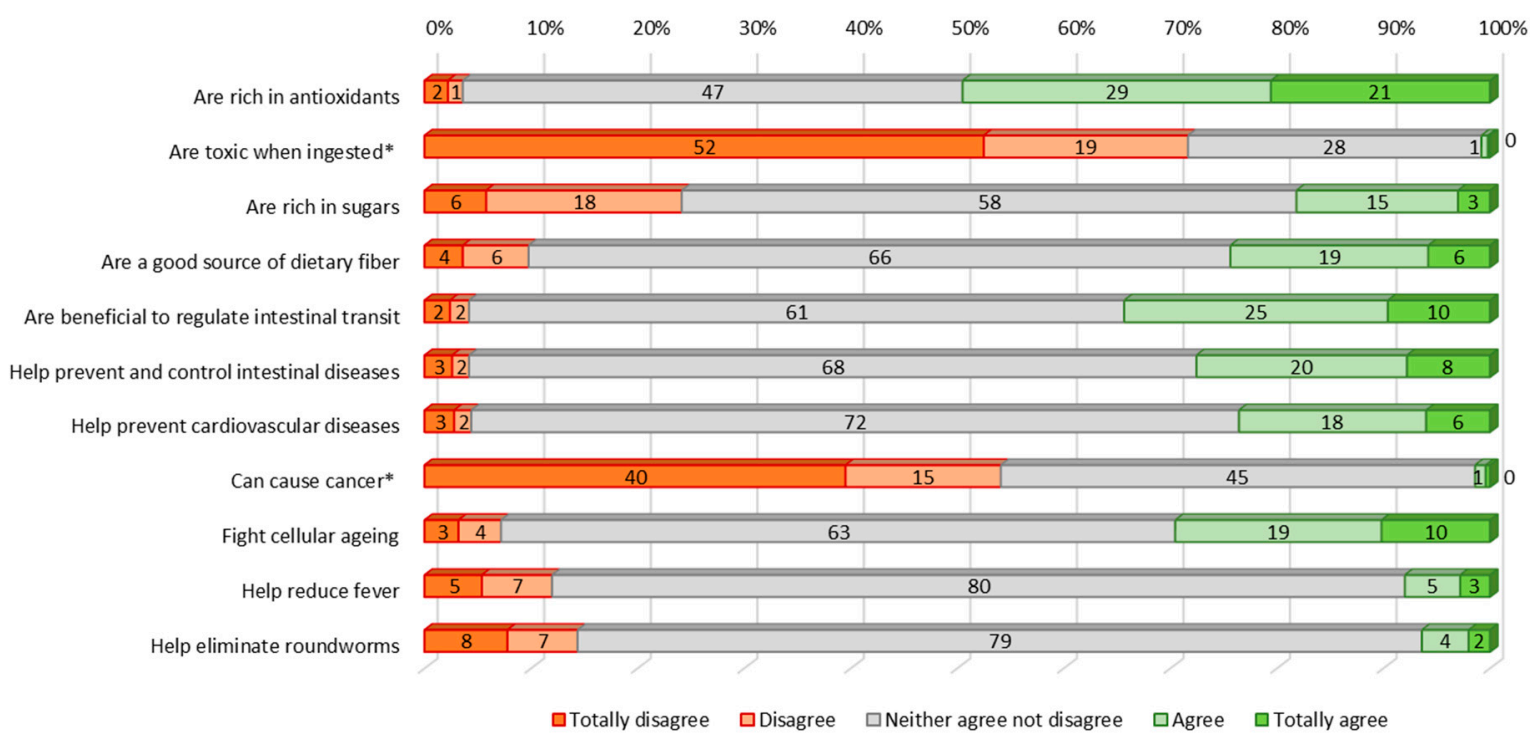

Figure 3. Level of agreement with statements related with knowledge about crowberries' nutritional characteristics and health effects (* denotes a false statement).

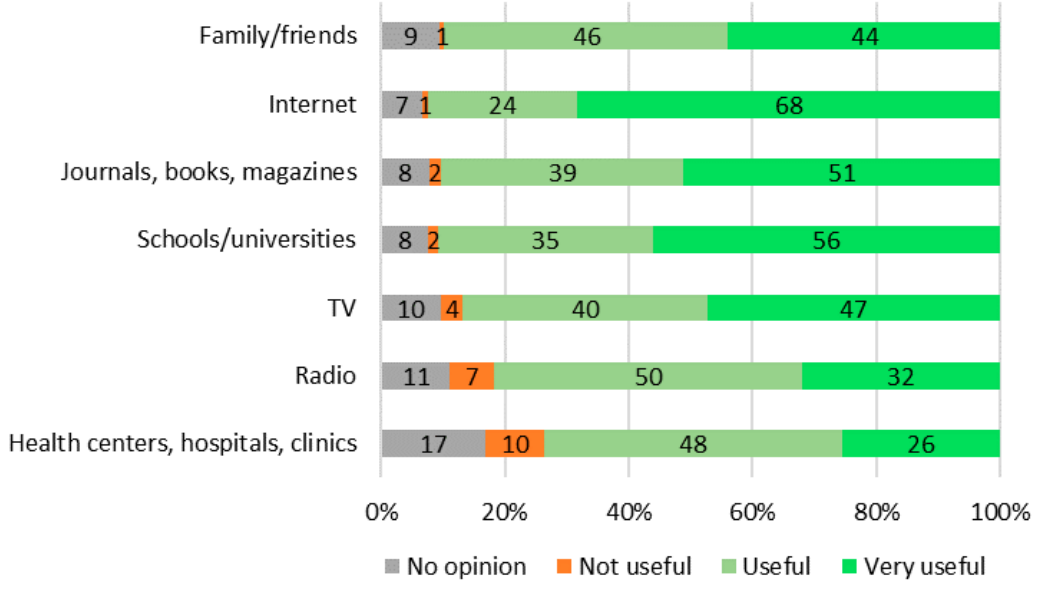

Figure 4. Opinion about the media that could be used to disseminate information about crowberries.

The statements used to measure the general knowledge about crowberries ( 8 items shown in Figure 2) plus those used to assess the knowledge about their nutritional composition and health effects (11 items in Figure 3 ) were gathered together into a global variable accounting for the global level of knowledge about crowberries (GLKC). All 19 statements were measured on a Likert scale from 1 to 5 ( 1 = totally disagree, $2=$ disagree, $3=$ no opinion, $4=$ agree and $5=$ totally agree). For each participant, the variable GLKC was computed as the average between the scores for all items, after reversing 4 items, which corresponded to false statements (identified in Figures 2 and 3 above). This variable was measured on a scale from 1 to 5 points. The level of knowledge was then evaluated for the global sample and in the different groups according to the sociodemographic variables, as shown in Table 1. The results show that for the global sample, the average score obtained was $3.59 \pm 0.51$, which is very close to the middle point of the scale. It was further observed that there were not significant differences between groups according to the living environment or type of profession, but significant differences were found for groups according to sex (the women showing a slightly higher average score), education (those with a university degree showing higher score), marital status (the ones living together with higher score) and employment (the higher sore being for those employed). As well, 
significant differences were found between age groups, specifically between young adults and adults, and also between young adults and senior adults.

Table 1. Level of knowledge according to the sociodemographic groups.

\begin{tabular}{|c|c|c|c|c|}
\hline Variable & Class & $\begin{array}{c}\text { GLKC }^{(1)} \\
(\mathbf{M} \pm \mathbf{S D})\end{array}$ & $p$-Value & Multiple Comparisons (Pairwise): $p$-Value \\
\hline \multirow[t]{4}{*}{ Age } & & & $<0.005^{(2)}$ & (young adults) versus (adults): $p<0.005$ \\
\hline & Young adults & $3.38 \pm 0.45$ & & (young adults) versus (senior adults): $p<0.005$ \\
\hline & Adults & $3.66 \pm 0.49$ & & (adults) versus (senior adults): $p=0.841$ \\
\hline & Senior adults & $3.64 \pm 0.54$ & & \\
\hline \multirow[t]{3}{*}{ Sex } & & & $<0.005^{(3)}$ & \\
\hline & Female & $3.60 \pm 0.51$ & & \\
\hline & Male & $3.56 \pm 0.53$ & & \\
\hline \multirow[t]{3}{*}{ Education Level } & & & $<0.005^{(3)}$ & \\
\hline & Up to 12 th grade (secondary) & $3.44 \pm 0.57$ & & \\
\hline & University degree & $3.64 \pm 0.49$ & & \\
\hline \multirow[t]{3}{*}{ Living environment } & & & $0.513^{(3)}$ & \\
\hline & Urban & $3.58 \pm 0.49$ & & \\
\hline & Rural/suburban & $3.60 \pm 0.55$ & & \\
\hline \multirow[t]{3}{*}{ Marital status } & & & $0.012^{(3)}$ & \\
\hline & Living together & $3.63 \pm 0.52$ & & \\
\hline & Living alone & $3.55 \pm 0.51$ & & \\
\hline \multirow[t]{3}{*}{ Employment status } & & & $0.001^{(3)}$ & \\
\hline & Employed & $3.65 \pm 0.48$ & & \\
\hline & Others & $3.46 \pm 0.57$ & & \\
\hline \multirow{3}{*}{$\begin{array}{l}\text { Professional of } \\
\text { nutrition }\end{array}$} & & & $0.688^{(3)}$ & \\
\hline & Yes & $3.61 \pm 0.60$ & & \\
\hline & No & $3.59 \pm 0.50$ & & \\
\hline \multirow[t]{3}{*}{ Professional of food } & & & $0.560^{(3)}$ & \\
\hline & Yes & $3.60 \pm 0.53$ & & \\
\hline & No & $3.59 \pm 0.51$ & & \\
\hline \multirow{3}{*}{$\begin{array}{l}\text { Professional of } \\
\text { agriculture }\end{array}$} & & & $0.110^{(3)}$ & \\
\hline & Yes & $3.67 \pm 0.53$ & & \\
\hline & No & $3.58 \pm 0.51$ & & \\
\hline \multirow[t]{3}{*}{ Professional of sales } & & & $0.561^{(3)}$ & \\
\hline & Yes & $3.62 \pm 0.56$ & & \\
\hline & No & $3.59 \pm 0.51$ & & \\
\hline \multirow[t]{3}{*}{ Professional of tourism } & & & $0.238^{(3)}$ & \\
\hline & Yes & $3.49 \pm 0.60$ & & \\
\hline & No & $3.60 \pm 0.51$ & & \\
\hline Global sample & & $3.59 \pm 0.51$ & Range: mini & $\mathrm{n}=1.84 ;$ maximum $=4.79$ \\
\hline
\end{tabular}

(1) GLKC—global level of knowledge about crowberries: Mean value \pm standard deviation, measured on a scale from 1 to 5 points.

(2) Kruskal-Wallis test at $5 \%$ level of significance $(p<0.05)$, with pairwise multiple comparisons. ${ }^{(3)}$ Mann-Whitney U test at $5 \%$ level of significance $(p<0.05)$.

The variable GLKC was then categorized into two groups as follows: without knowledge (average score below 3 ) or with knowledge (average score above 3). A tree classification analysis was performed for variable "Classes of GLKC" according to the sociodemographic variables (age, sex, education, living environment, marital status or employment status). All the variables were included in the obtained tree, which is presented in Figure 5, and the estimated risks for resubstitution and cross-validation were 0.168 (with standard error of 0.017 ) and 0.174 (standard error of 0.017), respectively. The tree has 4 levels and 17 nodes of which 9 are terminal. The results indicate that, considering the whole sample of 501 participants, most of them could be considered as having knowledge about crowberries $(83.2 \%)$ and only $16.8 \%$ revealed having no knowledge (node zero). The first level of depth was established based on the discriminant ability of variable education level, separating the most educated from the least educated participants. For the participants with lower levels of school, the following discriminating variable was age, leading to a terminal node for the 
young adults, while for the other age groups, the next discriminant was sex, and finally, for the women, the separation was made according to marital status, with those living together showing a higher number of participants with knowledge than those living alone ( $78.6 \%$ and $61.5 \%$, respectively). With respect to the participants with a university degree, the next discriminant was sex, and for the men, the knowledge was further discriminated according to living environment (higher knowledge for those living in urban environments, $85.0 \%$ ). For the women with a university degree, the employment status was the next discriminating variable, separating the employed as having higher knowledge than other groups (90.3\% versus $82.5 \%$, respectively). For the participants of other employment categories, the final separation occurred according to living environment-this time with participants from urban environments showing lower level of knowledge than those in rural or suburban areas ( $75.0 \%$ and $89.7 \%$ of participants with knowledge, respectively).

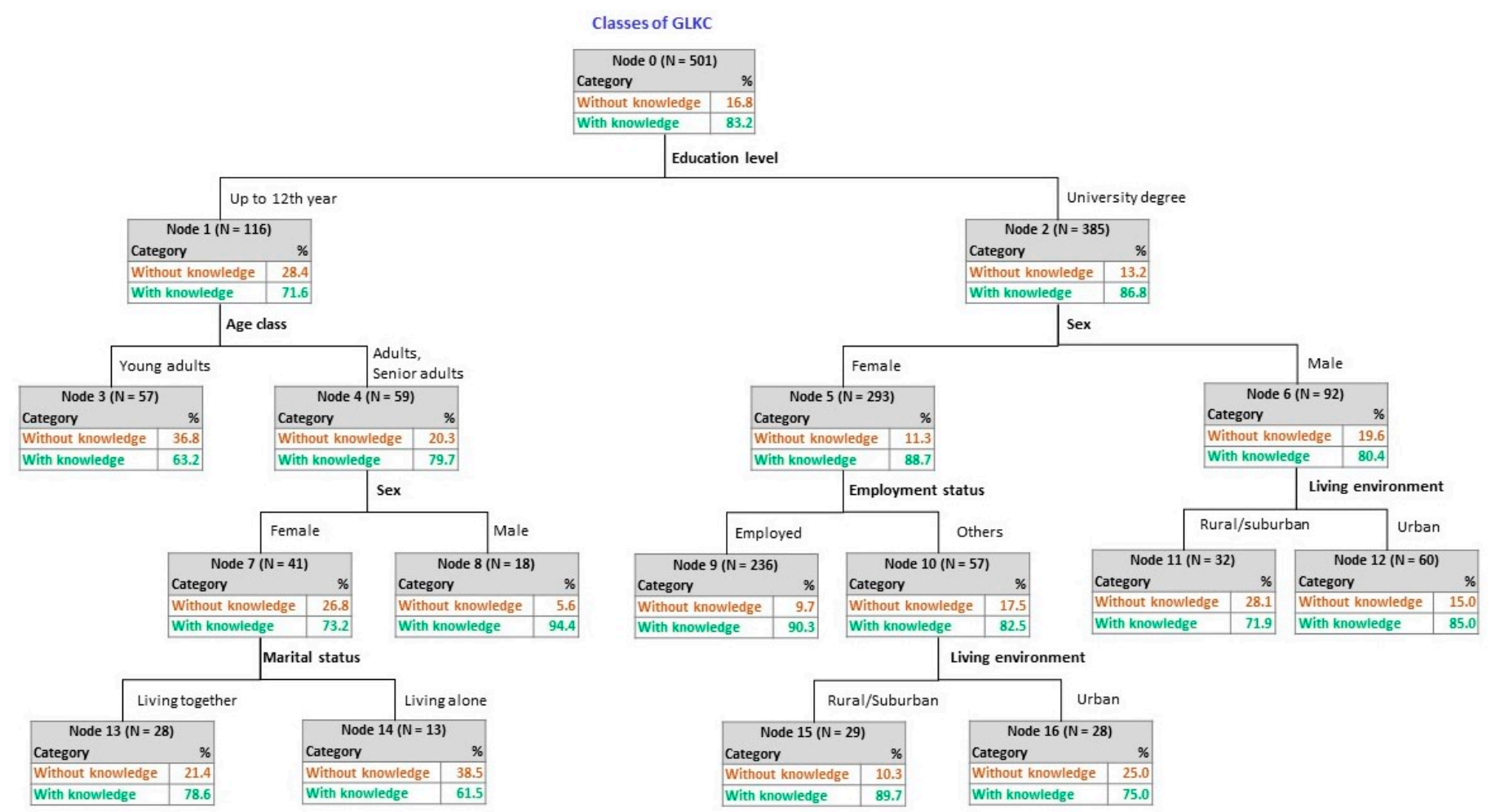

Figure 5. Tree classification for variable class of GLKC as a function of the sociodemographic variables.

\subsection{Consumption of Crowberries}

From the participants in the study, $61.9 \%$ had already consumed crowberries, while $25.7 \%$ had never consumed them. There were still $12.4 \%$ who said they do not know or do not remember having ever consumed them.

Regarding the frequency of consumption, $53.7 \%$ do not eat crowberries; $31.9 \%$ eat them seldom, around one time per year; $11.2 \%$ about twice a year and just a few eat them a little more (2.2\% eat about 6 times/year and $1.0 \%$ eat them 12 times/year.

From those who eat crowberries, 305 persons have consumed them fresh, but other ways of consumption were also cited, although with low expression: jelly (31 participants), liqueur $(n=12)$, dessert $(n=11)$, refreshment $(n=8)$, frozen fruit $(n=7)$, dish garnish $(n=4)$, ice cream or beer ( $n=3$ in both cases). In relation to obtaining the fruits, a great number of participants obtained them by collecting them in the wild; for 57 people, they were given by someone else, in that they bought them in local markets $(n=15)$, fairs $(n=5)$ or festivals/pilgrimages $(n=10)$.

Figure 6 presents the results of the opinions manifested by the participants referring to some organoleptic characteristics of the crowberries. A high percentage of the participants 
could not express their opinions about most of the aspects investigated, either because they did not know or did not remember (with percentages varying from 34 to $42 \%$ ). In global context, the opinion is that crowberries are juicy ( $25 \%$ of high intensity) but firm ( $17 \%$ of high intensity), and that the seeds are strongly felt when biting the fruit. Regarding the taste or aroma, an important fraction of the participants considers these attributes of low intensity ( $27 \%$ and $24 \%$, respectively).

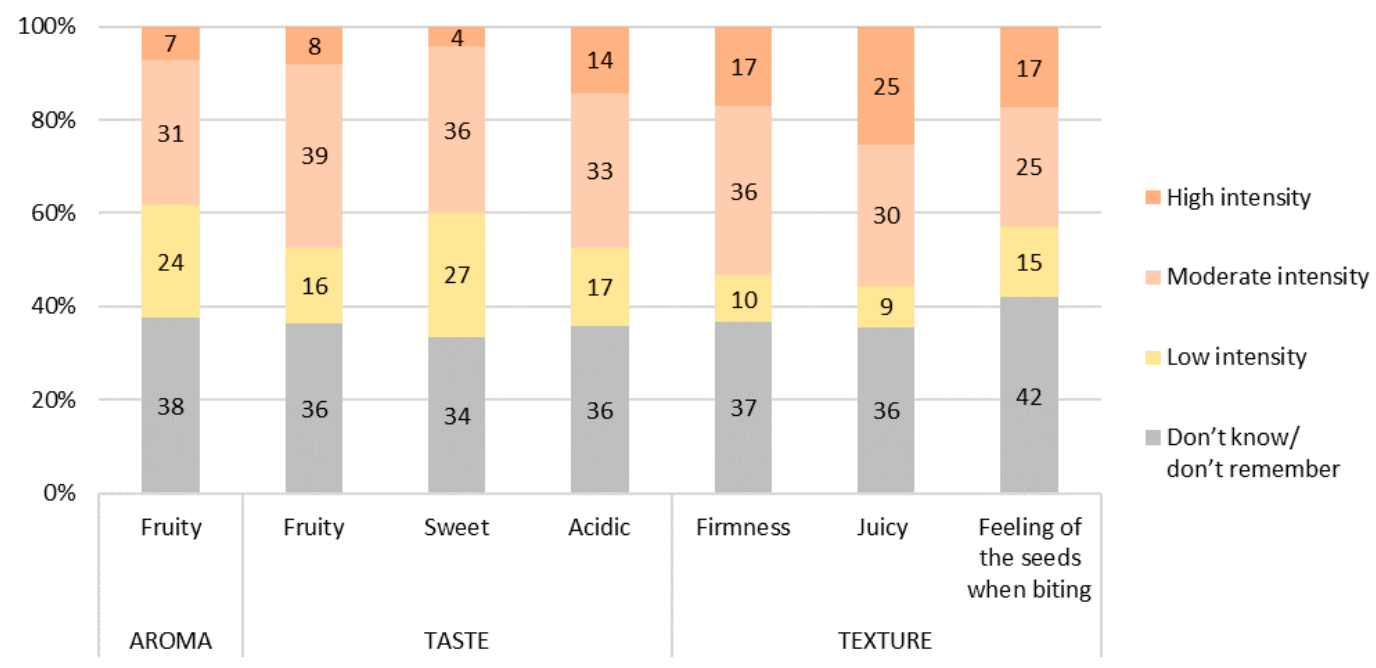

Figure 6. Opinion about the sensorial characteristics of the crowberries.

\subsection{Environmental and Social Aspects Linked with Crowberries}

When asked about the possible threat to the extension of this species, an important fraction of the participants consider crowberries as an endangered species $(41.1 \%)$, while $17.8 \%$ believe it is nearly endangered and $4.4 \%$ think it is not worrying. It was further observed that $36.7 \%$ admitted they do not have an opinion about this subject. Figure 7 refers to the opinion of the participants regarding the possible factors that can contribute to the threatening of the crowberry species. People seem to believe that the destruction of dunes $(80 \%)$, the reduced dissemination of information $(76 \%)$, the lack of knowledge about the potential of these fruits $(75 \%)$, forest fires $(74 \%)$, and urbanization of coastal areas $(72 \%)$ are the major threats to this species.

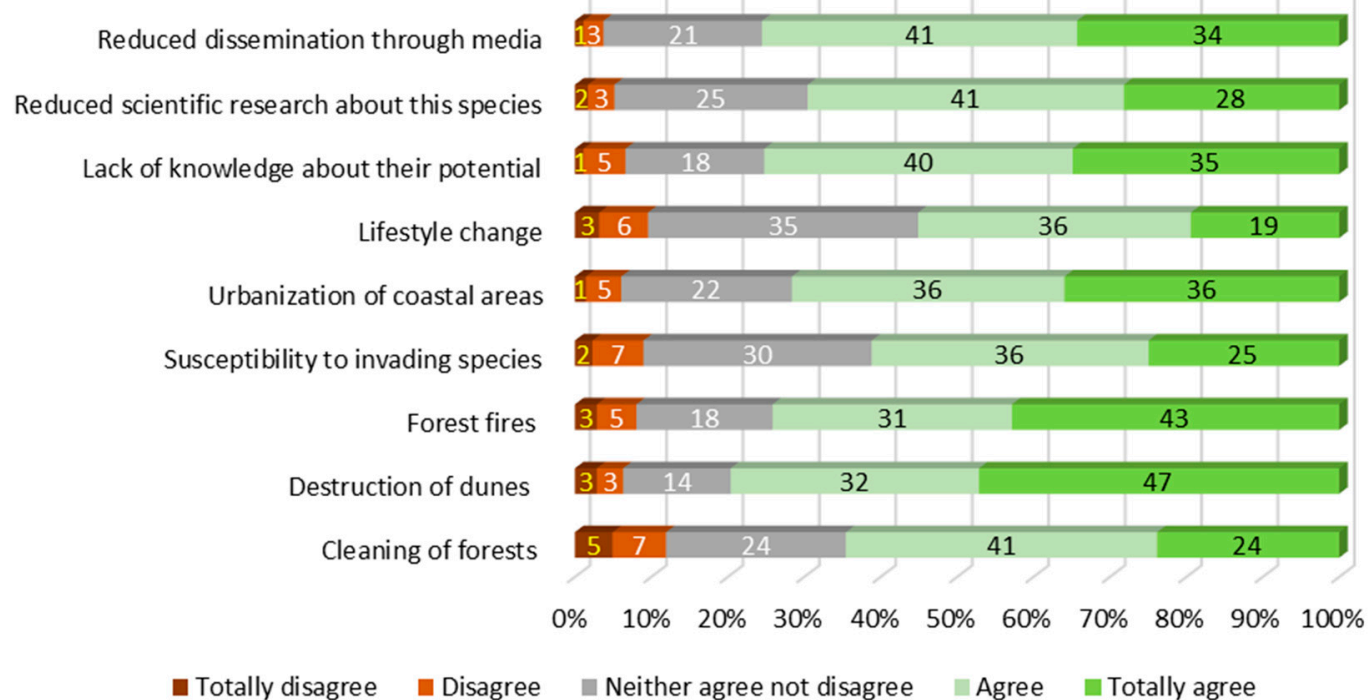

Figure 7. Possible factors contributing for the threatening of the crowberry species. 
The nine items considered as possible threats to the crowberry were submitted to a factor analysis, which was a statistical technique suitable for the data because the results of the Bartlett's test ensured a significant $p$-value $(p<0.0005)$, leading to the rejection of the null hypothesis H0: "The correlation matrix is equal to the identity matrix". Additionally, the value of the KMO measure of adequacy was good (0.859), attending to the classification proposed by Kaiser and Rice [32]. Analysis of the anti-image matrix revealed that all the values of MSA (Measure of Sampling Adequacy) were higher than 0.5 (varying between 0.834 and 0.893 ), which indicates that all the variables should be included in the analysis.

The rotated solution required three iterations to converge and extracted two factors, explaining $53.0 \%$ of total variance (F1-28.8\% and F2-24.2\%). According to the communalities, the variable which had the highest fraction of its variance explained by the solution $(78.9 \%$ ) was V8 (corresponding to item: Reduced scientific research about this species). However, the variable V1 (Cleaning of forests) had a lower percentage of variance explained $(22.9 \%)$. Table 2 presents the results of FA, i.e., the two factors and the contributing variables. Factor F1 included aspects related mostly to human actions and malpractices and/or natural disasters, while factor F2 was linked to the lack of information and knowledge about this species. The highest factor loadings for F1 were 0.776 and 0.639 , corresponding to the urbanization of coastal areas (V5) and the destruction of dunes (V2), while for F2, the variables contributing more for the definition of the factor were V8 (reduced scientific research about this species) and V9 (reduced dissemination through media), with loadings of 0.842 and 0.772 , respectively.

Table 2. Factor analysis to the possible causes that can contribute to the endangerment of the crowberry species.

\begin{tabular}{lcc}
\hline \multicolumn{1}{c}{ Variable } & \multicolumn{2}{c}{ Factor Loadings } \\
\cline { 2 - 3 } & F1 & F2 \\
\hline V1. Cleaning of forests & 0.442 & \\
V2. Destruction of dunes & 0.639 & \\
V3. Forest fires & 0.469 & \\
V4. Susceptibility to invading species & 0.563 & \\
V5. Urbanization of coastal areas & 0.776 & 0.620 \\
V6. Lifestyle change & 0.575 & 0.842 \\
V7. Lack of knowledge about their potential & & 0.772 \\
V8. Reduced scientific research about this species & & \\
V9. Reduced dissemination through media & & \\
\hline
\end{tabular}

F1: Human action and natural disasters; F2: Lack of information and knowledge.

The solution was validated though the Cronbach's alpha $(\alpha)$, which measures the internal consistency within each of the factors [28]. The values of Cronbach's alpha for F1 and F2 were, respectively, 0.878 and 0.817 , which can be classified as good [33-35]. Moreover, in none of the cases, the elimination of any of the variables would lead to an increase in the value of alpha, thus confirming the suitability of all the variables included in both factors.

\section{Discussion}

The majority of participants know the berry "camarinha", but the level of knowledge depends on age, decreasing from senior adults to young adults. Indeed, the old adults could have memories of selling berries in traditional commerce and streets near the beach. On the other hand, the majority of young people also know the berries, but their knowledge could be, mainly, obtained from the internet, or journals and magazines that were considered the most appropriate media to disseminate the information about crowberries. Indeed, since 2018, the project IDEAS4life that supports this work developed efforts at various levels towards wide dissemination of the information to the scientific community and the general public through media press releases, paper/digital journals, and participation in local and national radio programs and workshops. Other factors that contribute to the 
higher knowledge were the high level of education, the marital status (living together), employment (people employed) and sex (female). On the other hand, the type of profession does not influence the level of knowledge, even in areas related to food, nutrition, and agriculture. This can be due to the decrease of their production, harvesting, and the inexistence of locals to buy these berries. Probably, the knowledge about the berries, especially among adults and senior adults, had been related to childhood memories that were fallen by the wayside and that have been revived by the dissemination of information about the crowberries.

Globally, the participants are well informed about the berry plant and berry appearance (color and size), but only about one third know or remember that the berry has seeds (usually three seeds, with a proportion of $54.97 \%$ (dry basis) of weight) [9]. This can be related to the very scarce consumption in Portugal that results from the current inexistence of markets that sell these berries. This aspect can also be related to the lack of knowledge of participants about the nutritional characteristics of these berries, such as their content in sugar and dietary fiber. Moreover, nearly half of the participants do not know or do not remember what is the taste, aroma and texture of crowberries. About two thirds of the participants referred that they already consumed crowberries, which implies that they, at least once, were introduced to this small fruit. However, the frequency of consumption is very low, with about half of participants referring that they do not eat crowberries, and nearly the other half eat them only once per year, probably during a trip to the beach or to the coast, when they could find them on sale on the street, more than 30 years ago. In fact, only a very low proportion of people admit they consume them more than one time per year, in which case, they collected the berries themselves from the wild, thus not requiring commercialization. Trade of these berries is actually very scarce, either due to low abundance of the fruits or to low interest in harvesting or buying them. The way of consumption was mainly fresh but, in some cases, they were consumed in jelly, liqueur, dessert, as a refreshment, frozen fruit, garnish of a dish, ice cream or beer. These alternative forms of use of the crowberries date back from old traditions among the coastal peoples, when the abundance of these plants was vast, providing huge amounts of berries that people collected and processed in order to overcome their perishability.

In the same way, the participants revealed a low level of knowledge about the health benefits of crowberries. Even at low percentages, the participants recognized in crowberries the general health effects of berries, such as antioxidant activity, protection against degenerative diseases associated with oxidative stress (cardiovascular diseases, cancer and cellular ageing) [15]. However, the reduction of fevers and the capacity to kill intestinal worms that are associated with crowberries in traditional medicine [6] was only identified by a few participants. These facts confirm the need to further study the nutritive and bioactive properties of these small fruits as well as their possible health effects, and to disseminate this information adequately as a way to promote the consumption and preservation of this plant, or even incentivize its possible planting as shrub fields/orchards, as it happens nowadays in Portugal with other berries such as blueberries, raspberries or physalises [36,37].

The low level of knowledge about white crowberries could be related to the perception among the participants that the information available about these berries is very scarce. To disseminate information about crowberries, the participants considered as being more useful their family and friends, the internet, journals, books and magazines, schools/universities followed by radio and health institutions.

Currently, this endemic shrub of the Atlantic coastal dunes of the Iberian Peninsula has been classified as a vulnerable species in Andalusia and Galicia, Spain [35,36]. However, only less than half of the participants considered the $C$. album as an endangered species. The main causes referred to as related with the loss of habitat were aspects linked mostly to human actions, such as the destruction of dunes and the urbanization of coastal areas, and the lack of information and knowledge about the potential of this berry species. This might be attributed to the reduced dissemination of information through the media and to 
the scarce scientific research done to better understand this species and its benefits. The relative rarity of scientific work done on the C. album can be due to the limited current distribution of this plant, but it is hoped that the R\&D project, IDEAS4life that supports this work, can contribute to raise awareness of this species and alert to the need to preserve this important plant in the Southern European Atlantic coast's biodiversity heritage.

\section{Conclusions}

This work showed that the consumption of white crowberry in Portugal is scarce, its commercialization is practically non-existent, and the level of knowledge of the general population about this small fruit is very limited. Although knowing that this is a bush normally growing by the beach and in sandy areas, people are not familiar with the berries' organoleptic characteristics and certainly not aware of their nutritional value and possible health effects, with exception of the antioxidant activity attributed to them. However, when it comes to the endangerment of crowberry species, people seem aware of the possible factors that contribute to threatening this plant.

Although producing some valuable insights into the issues related with this nonconventional berry, this study has some limitations, such as the recruitment of the sample being by convenience and consisting of uneven group representativeness (for example, more women than men). Additionally, this berry bush is endogenous to the Atlantic coast of Europe in the Iberian Peninsula, therefore, the Spanish region of Galicia might also be an interesting area to extend this research in future work.

Supplementary Materials: The following are available online at https://www.mdpi.com/article/10 .3390/app11125463/s1, S1 Questionnaire.

Author Contributions: Conceptualization, A.M.d.S., M.J.B. and R.P.F.G.; methodology, A.M.d.S., M.J.B. and R.P.F.G.; software, R.P.F.G.; validation, M.J.B. and R.P.F.G.; formal analysis, R.P.F.G.; investigation, A.M.d.S., M.J.B. and R.P.F.G.; resources, A.M.d.S., M.J.B. and R.P.F.G.; data curation, R.P.F.G.; writing—original draft preparation, A.M.d.S., M.J.B. and R.P.F.G.; writing—review and editing, R.P.F.G.; visualization, R.P.F.G.; supervision, R.P.F.G.; project administration, M.J.B.; funding acquisition, A.M.d.S., M.J.B. and R.P.F.G. All authors have read and agreed to the published version of the manuscript.

Funding: This research was funded by Fundação para a Ciência e a Tecnologia (FCT) (UIDB/00070/2020) and the European Regional Development Fund (FEDER), through: Portugal 2020_POCI-01-0145FEDER-029305, IDEAS4life-Novos IngreDiEntes Alimentares de Plantas MarítimaS; and Centro 2020 - Centro-01-0145-FEDER-000007, Project ReNATURE—Valorization of the Natural Endogenous Resources of the Centro Region.

Institutional Review Board Statement: The study was conducted according to the guidelines of the Declaration of Helsinki, and approved by the Ethics Committee of Polytechnic Institute of Viseu (reference 22/SUB/2021).

Informed Consent Statement: Informed consent was obtained from all subjects involved in the study.

Data Availability Statement: The data are available from the author, Raquel Guiné, upon request.

Acknowledgments: The authors would like to thank the CERNAS Research Centre and the Polytechnic Institutes of Viseu and Coimbra for their support.

Conflicts of Interest: The authors declare no conflict of interest.

\section{References}

1. Lopez-Doriga, I. The Archaeobotany and Ethnobotany of Portuguese or White Crowberry (Corema album). Ethnobiol. Lett. 2018, 9, 19-32. [CrossRef]

2. Hellmann, C.; Grosse-Stoltenberg, A.; Thiele, J.; Oldeland, J.; Werner, C. Heterogeneous Environments Shape Invader Impacts: Integrating Environmental, Structural and Functional Effects by Isoscapes and Remote Sensing. Sci. Rep. 2017, 7. [CrossRef]

3. Barroca, M.J.; Moreira da Silva, A. From folklore to the nutraceutical world: The Corema album potential. In Gastronomy and Food Science; Elsevier: Amsterdam, The Netherlands, 2020; pp. 119-134. 
4. $\quad$ Blanca, G.; Cabezudo, B.; Hernández-Bermejo, J.E.; Herrera, C.M.; Muñoz, J.; Valdés, B. Libro Rojo de La Flora Silvestre Amenazada de Andalucía; Tomo II Especies Vulnerables; Consejería de Medio Ambiente: Seville, Spain, 2000.

5. Gil-López, M.J. Etnobotánica de la camarina (Corema album, Empetraceae) en Cádiz. Acta Bot. Malacit. 2011, 36, 137-144. [CrossRef]

6. Oliveira, P.B.; Dale, A. Corema album (L.) D. Don, the White Crowberry-A New Crop. J. Berry Res. 2012, 2, 123-133. [CrossRef]

7. Andrade, S.C.; Gonçalves, F.; Guiné, R. Contribution for the Physical-Chemical Characterization of Portuguese Crowberry (Corema album). Int. J. Food Sci. Nutr. 2017, 2, 9-14.

8. Calviño-Cancela, M. Ingestion and Dispersal: Direct and Indirect Effects of Frugivores on Seed Viability and Germination of Corema album (Empetraceae). Acta Oecologica 2004, 26, 55-64. [CrossRef]

9. León-González, A.J.; Truchado, P.; Tomás-Barberán, F.A.; López-Lázaro, M.; Barradas, M.C.D.; Martín-Cordero, C. Phenolic Acids, Flavonols and Anthocyanins in Corema album (L.) D. Don Berries. J. Food Compos. Anal. 2013, 29, 58-63. [CrossRef]

10. Pimpão, R.C.; Dew, T.; Oliveira, P.B.; Williamson, G.; Ferreira, R.B.; Santos, C.N. Analysis of Phenolic Compounds in Portuguese Wild and Commercial Berries after Multienzyme Hydrolysis. J. Agric. Food Chem. 2013, 61, 4053-4062. [CrossRef]

11. Martínez-Varea, C.M.; Ferrer-Gallego, P.P.; Raigón, M.D.; Badal, E.; Ferrando-Pardo, I.; Laguna, E.; Real, C.; Roman, D.; Villaverde, V. Corema album Archaeobotanical Remains in Western Mediterranean Basin. Assessing Fruit Consumption during Upper Palaeolithic in Cova de Les Cendres (Alicante, Spain). Quat. Sci. Rev. 2019, 207, 1-12. [CrossRef]

12. Santos, M.S.; de Oliveira, C.M.; Valdiviesso, T.; de Oliveira, P.B. Effects of Pretreatments on Corema album (L.) D. Don (Subsp. Album) Seeds' Germination. J. Berry Res. 2014, 4, 183-192. [CrossRef]

13. Simões, L.M.d.S. Desenvolvimento de Estratégias para a Valorização de uma Planta Endógena da Costa Marítima Portuguesa. Master's Thesis, Escola Superior Agrária de Coimbra, Coimbra, Portugal, 2018.

14. Macedo, D.; Tavares, L.; McDougall, G.J.; Vicente Miranda, H.; Stewart, D.; Ferreira, R.B.; Tenreiro, S.; Outeiro, T.F.; Santos, C.N. (Poly)Phenols Protect from $\alpha$-Synuclein Toxicity by Reducing Oxidative Stress and Promoting Autophagy. Hum. Mol. Genet. 2015, 24, 1717-1732. [CrossRef]

15. Scalbert, A.; Manach, C.; Morand, C.; Rémésy, C.; Jimenez, L. Dietary Polyphenols and the Prevention of Diseases. Crit. Rev. Food Sci. Nutr. 2005, 45, 287-306. [CrossRef] [PubMed]

16. Jardim, C.; Macedo, D.; Figueira, I.; Dobson, G.; McDongall, G.J.; Stewart, D.; Ferreira, R.B.; Menezes, R.; Santos, C.N. (Poly)Phenol Metabolites from Arbutus Unedo Leaves Protect Yeast from Oxidative Injury by Activation of Antioxidant and Protein Clearance Pathways. J. Funct. Foods 2017, 32, 333-346. [CrossRef]

17. León-González, A.J.; Mateos, R.; Ramos, S.; Martín, M.Á.; Sarriá, B.; Martín-Cordero, C.; López-Lázaro, M.; Bravo, L.; Goya, L. Chemo-Protective Activity and Characterization of Phenolic Extracts from Corema album. Food Res. Int. 2012, 49, 728-738. [CrossRef]

18. Guiné, R.P.F.; Florença, S.G.; Villalobos Moya, K.; Anjos, O. Edible Flowers, Old Tradition or New Gastronomic Trend: A First Look at Consumption in Portugal versus Costa Rica. Foods 2020, 9, 977. [CrossRef]

19. Guiné, R.P.F.; Florença, S.G.; Barroca, M.J.; Anjos, O. The Link between the Consumer and the Innovations in Food Product Development. Foods 2020, 9, 1317. [CrossRef] [PubMed]

20. Triola, M.F.; Flores, V.R.L.F. Introdução à Estatística, 12th ed.; LTC: Rio de Janeiro, Brasil, 2017.

21. Levin, J.; Fox, J.A. Estatística Para Ciências Humanas, 9th ed.; Pearson: Rio de Janeiro, Brasil, 2004.

22. Fundação Francisco Manuel dos Santos: PORDATA—Base de Dados Portugal Contemporâneo. Available online: https://www. pordata.pt/Home (accessed on 10 December 2020).

23. Cochran, W.G. Sampling Techniques, 3rd ed.; John Wiley \& Sons: New York, NY, USA, 1977.

24. Levine, D.M.; Stephan, D.F.; Krehbiel, T.C.; Berenson, M.L. Estatística: Teoria e Aplicacõess Usando o Microsoft Excel, 5th ed.; LTC: Rio de Janeiro, Brasil, 2008; ISBN 978-85-216-1634-4.

25. Florença, S.G.; Correia, P.M.R.; Costa, C.A.; Guiné, R.P.F. Edible Insects: Preliminary Study about Perceptions, Attitudes, and Knowledge on a Sample of Portuguese Citizens. Foods 2021, 10, 709. [CrossRef]

26. Guiné, R.P.F.; Florença, S.G.; Ferrão, A.C.; Bizjak, M.Č.; Vombergar, B.; Simoni, N.; Vieira, V. Factors Affecting Eating Habits and Knowledge of Edible Flowers in Different Countries. Open Agric. 2021, 6, 67-81. [CrossRef]

27. Guiné, R.P.F.; Correia, P.; Leal, M.; Rumbak, I.; Barić, I.C.; Komes, D.; Satalić, Z.; Sarić, M.M.; Tarcea, M.; Fazakas, Z.; et al. Cluster Analysis to the Factors Related to Information about Food Fibers: A Multinational Study. Open Agric. 2020, 5, 593-606. [CrossRef]

28. Broen, M.P.G.; Moonen, A.J.H.; Kuijf, M.L.; Dujardin, K.; Marsh, L.; Richard, I.H.; Starkstein, S.E.; Martinez-Martin, P.; Leentjens, A.F.G. Factor Analysis of the Hamilton Depression Rating Scale in Parkinson's Disease. Parkinsonism Relat. Disord. 2015, 21, 142-146. [CrossRef]

29. Stevens, J.P. Applied Multivariate Statistics for the Social Sciences, 5th ed.; Routledge: New York, NY, USA, 2009; ISBN 978-0-80585903-4.

30. Rohm, A.J.; Swaminathan, V. A Typology of Online Shoppers Based on Shopping Motivations. J. Bus. Res. 2004, 57, 748-757. [CrossRef]

31. Tanaka, K.; Akechi, T.; Okuyama, T.; Nishiwaki, Y.; Uchitomi, Y. Development and Validation of the Cancer Dyspnoea Scale: A Multidimensional, Brief, Self-Rating Scale. Br. J. Cancer 2000, 82, 800-805. [CrossRef] [PubMed]

32. Kaiser, H.F.; Rice, J. Little Jiffy, Mark Iv. Educ. Psychol. Meas. 1974, 34, 111-117. [CrossRef] 
33. Hair, J.F.H.; Black, W.C.; Babin, B.J.; Anderson, R.E. Multivariate Data Analysis, 7th ed.; Prentice Hall: Hoboken, NJ, USA, 2009; ISBN 978-0-13-813263-7.

34. Maroco, J.; Garcia-Marques, T. Qual a fiabilidade do alfa de Cronbach? Questões antigas e soluções modernas? Laboratório Psicol. 2006, 4, 65-90. [CrossRef]

35. Davis, F.B. Educational Measurements Their Interpretation; Wadsworth Publishing Co.: Belmont, CA, USA, 1964.

36. Vieira, J.M.; Flores-López, M.L.; de Rodríguez, D.J.; Sousa, M.C.; Vicente, A.A.; Martins, J.T. Effect of Chitosan-Aloe Vera Coating on Postharvest Quality of Blueberry (Vaccinium corymbosum) Fruit. Postharvest Biol. Technol. 2016, 116, 88-97. [CrossRef]

37. Gomes, S.M.C.; Ghica, M.-E.; Rodrigues, I.A.; de Souza Gil, E.; Oliveira-Brett, A.M. Flavonoids Electrochemical Detection in Fruit Extracts and Total Antioxidant Capacity Evaluation. Talanta 2016, 154, 284-291. [CrossRef] 